\title{
PENGARUH INDEKS MASSA TUBUH (IMT) TERHADAP KEJADIAN HIPERTENSI PADA WANITA USIA SUBUR (WUS) DI WILAYAH PUSKESMAS PULO BRAYAN MEDAN TAHUN 2017
}

\author{
Debora Lestari Simamora ${ }^{1}$, Heru Santosa ${ }^{2}$, Sorimuda Sarumpaet ${ }^{3}$ \\ ${ }^{1}$ Ilmu Kesehatan Masyarakat, Universitas Sumatera Utara \\ Email: hilbramgavriel@gmail.com \\ ${ }^{2}$ Departemen Kependudukan dan Biostatistik, Universitas Sumatera Utara \\ ${ }^{3}$ Departemen Epidemologi, Universitas Sumatera Utara
}

Masuk: 06-03-2018, revisi: 06-08-2019, diterima untuk diterbitkan:12-08-2019

\begin{abstract}
ABSTRAK
Berdasarkan data Puskesmas Pulo Brayan Medan bahwa jumlah penderita hipertensi selama 3 tahun terakhir mengalami peningkatan. Tahun 2014 jumlah penderita hipertensi 378 orang, tahun 2015 sebanyak 384 orang, dan tahun 2016 sebanyak 394 orang. Dari 394 penderita hipertensi tersebut, sebanyak 214 orang adalah WUS Banyak faktor yang diduga menjadi penyebab hipertensi pada WUS, salah satunya indeks massa tubuh (IMT). Tujuan penelitian ini untuk menganalisis pengaruh indeks massa tubuh terhadap kejadian hipertensi pada WUSPenelitian ini adalah penelitian analitik dan bersifat kuantitatif dengan rancangan kasus kontrol (case control). Penelitian dilakukan di wilayah Puskesmas Pulo Brayan Medan. Populasi penelitian sebanyak 8.547 orang dan sampel diperoleh sebanyak 166 orang yang dibagi menjadi 2 kelompok, masing-masing 83 orang. Analisis data menggunakan analisis univariat, analisis bivariat dengan chi-square dengan tingkat kepercayaan $95 \%(\square=0,05)$. Hasil penelitian menunjukkan bahwa indeks massa tubuh kelompok kasus dalam kategori obesitas (69,9\%), pada kelompok kontrol, responden yang obesitas (7,2\%). Variabel indeks massa tubuh (IMT) berpengaruh terhadap kejadian hipertensi pada WUS di wilayah Puskesmas Pulo Brayan Medan, p < 0,05. Disarankan kepada Kepala Puskesmas Pulo Brayan Medan untuk menginformasikan kepada WUS agar menjaga pola makan dan melakukan gaya hidup sehat serta melakukan pemeriksaan tekanan darah secara rutin di puskesmas agar diketahui sejak dini komplikasi lain yang dapat menyertai peningkatan tekanan darah.
\end{abstract}

Kata Kunci: Indeks Massa Tubuh; Hipertensi; Wanita usia subur (WUS)

\begin{abstract}
Based on data from the Medan Pulo Brayan Puskesmas that the number of hypertensive sufferers over the past 3 years has increased. In 2014 there were 378 people with hypertension, in 2015 there were 384 people, and in 2016 there were 394 people. Of the 394 people with hypertension, 214 people are WUS. Many factors are thought to be the cause of hypertension in WUS, one of them is body mass index (BMI). The purpose of this study was to analyze the effect of body mass index on the incidence of hypertension in WUS. This study is an analytical and quantitative study with a case control design. The study was conducted in the area of Pulo Brayan Puskesmas Medan. The study population was 8,547 people and the sample was 166 people divided into 2 groups, 83 people each. Data analysis used univariate analysis, bivariate analysis with chi-square with a confidence level of $95 \%(\square=0.05)$. The results showed that the body mass index of the case group was in the obesity category (69.9\%), in the control group, respondents were obese (7.2\%). Body mass index (BMI) variable influences the incidence of hypertension in WUS in the Pulo Brayan Puskesmas area, $p<0.05$. It is recommended to the Head of the Pulo Brayan Medan Puskesmas to inform WUS to maintain a healthy diet and lifestyle and to carry out routine blood pressure checks at the puskesmas so that other complications can be identified early on that can accompany an increase in blood pressure.
\end{abstract}

Keywords: Body Mass Index; Hypertension; Women of childbearing age (WUS) 


\section{PENDAHULUAN}

\section{Latar Belakang}

Data World Health Organization (WHO) tahun 2013 menunjukkan sekitar 972 juta orang atau 26,4\% penduduk di seluruh dunia menderita hipertensi dan diperkirakan pada tahun 2025 menjadi 1,15 milyar atau sekitar 29\% dari total penduduk dunia. Sebanyak 333 juta (proporsi $34,26 \%$ ) berada di negara maju dan 639 juta $(65,74 \%)$ berada di negara berkembang. Prevalensi hipertensi lebih tinggi di Afrika $46 \%$ pada dewasa 25 tahun ke atas dan paling rendah dengan prevalensi 35\% di Amerika (James, 2014).Data penelitian terakhir, bahwa terdapat sekitar 50 juta $(21,7 \%)$ orang dewasa Amerika menderita hipertensi.

Hipertensi juga menyerang Thailand sebesar $17 \%$ dari total penduduk, Vietnam 34,6\%, Singapura 24,9\%, Malaysia 29,9\% dan Indonesia 15\%. Dalam hal ini 15\% dari 230 juta penduduk Indonesia yaitu hampir 35 juta penduduk Indonesia terkena hipertensi (Muhamaddun, 2014). Berdasarkan Riskesdas 2007, hipertensi merupakan penyebab kematian nomor tiga $(6,8 \%)$ di Indonesia setelah stroke $(15,4 \%)$ dan penyakit tuberkulosis. Prevalensi hipertensi pada umur 18 tahun ke atas berdasarkan hasil pengukuran sebesar 31,7\%, pada perempuan sebesar 31,9\% dan laki-laki 31,3\%. Hasil Riskesdas 2013, menunjukkan penurunan prevalensi hipertensi menjadi $25,8 \%$, perempuan $28,8 \%$ dan laki-laki 22,8\%. Hipertensi pada perempuan cenderung lebih tinggi dibanding laki-laki (Kemenkes RI, 2013). Prevalensi hipertensi di Sumatera Utara menurut Riskesdas tahun 2013 adalah 5,8\% dari seluruh penduduk dan menduduki urutan keempat dari sepuluh penyakit tidak menular di Provinsi Sumatera Utara (Dinkes Propsu, 2013).Indeks massa tubuh diduga dapat menyebabkan terjadinya hipertensi. Lemak yang tersimpan di tubuh akan menyebabkan kenaikan berat badan sehingga mempengaruhi indeks massa tubuh (IMT) seseorang. Apabila akseptor mengalami obesitas maka akan lebih beresiko mengalami penyakit degeneratif seperti diabetes melitus, tekanan darah tinggi, jantung koroner bahkan stroke (Setyarini, 2013).

Puskesmas Pulo Brayan adalah salah satu puskesmas yang ada di Kota Medan. Berdasarkan data yang diperoleh dari bagian administrasi puskesmas, bahwa jumlah penderita hipertensi selama 3 tahun mengalami peningkatan. Pada tahun 2014 jumlah kunjungan sebanyak 20173 kunjungan dan jumlah penderita hipertensi sebanyak 378 orang. Tahun 2015 jumlah kunjungan pasien sebanyak 20089 dan jumlah penderita hipertensi sebanyak 384 orang. Tahun 2016 jumlah kunjungan seluruh pasien sebanyak 19976 kunjungan, sedangkan jumlah penderita hipertensi sebanyak 394 orang. Berdasarkan data tahun 2016, bahwa dari 394 penderita hipertensi tersebut, sebanyak 214 orang adalah wanita usia subur (WUS).Berdasarkan Survei pendahuluan yang peneliti lakukan dengan melakukan pemeriksaan tekanan darah pada 20 orang yang berkunjung ke Puskesmas Pulo Brayan diketahui bahwa sebanyak 11 orang mengalami hipertensi dengan tekanan darah sistolik >140 mmHg dan tekanan darah diastolik >90 mmHg dan sebanyak 9 orang dengan tekanan darah normal.

\section{METODE PENELITIAN Jenis Penelitian}

Penelitian ini merupakan penelitian analitik dan bersifat kuantitatif dengan rancangan kasus kontrol (case control), dimana meneliti peristiwa yang telah terjadi dan melihat ke belakang untuk mengetahui faktor-faktor yang dapat menimbulkan kejadian tersebut untuk mengungkap faktor yang melatarbelakangi terjadinya hipertensi pada wanita usia subur (WUS) 


\section{Besar Sampel}

Tabel 1. Hasil Penelitian Terdahulu

\begin{tabular}{|c|c|c|c|c|c|c|}
\hline No & $\begin{array}{l}\text { Peneliti } \\
\text { (tahun) }\end{array}$ & Judul & Variabel & OR & P1 & $\mathbf{P 2}$ \\
\hline 1 & $\begin{array}{l}\text { Dien } \\
(2014)\end{array}$ & $\begin{array}{l}\text { Hubungan Indeks Massa } \\
\text { Tubuh (IMT) Dengan } \\
\text { Tekanan Darah pada } \\
\text { Penderita Hipertensi di } \\
\text { Poliklinik Hipertensi Dan } \\
\text { Nefrologi BLU RSUP Prof. } \\
\text { DR. R.D. Kandou Manado }\end{array}$ & $\begin{array}{l}\text { Indeks Massa } \\
\text { Tubuh (IMT) }\end{array}$ & 2,680 & 0,35 & 0,54 \\
\hline
\end{tabular}

$$
\mathrm{n}_{1}=\mathrm{n}_{2}=\frac{\left(z_{\alpha} \sqrt{2 P Q}+z_{\beta}{\sqrt{P_{1} Q_{2}+P_{2} Q_{2}}}^{2}\right.}{\left(P_{1}-P_{2}\right)^{2}}
$$

Dimana:

$$
\mathrm{P}_{1}=\frac{O R \cdot P_{2}}{\left(1-P_{2}\right)+\left(O R \cdot p_{2}\right)}
$$

Keterangan:

$$
\begin{array}{ll}
\mathrm{n} & =\text { Besar sampel } \\
\mathrm{Z}_{\square} & =1,96 \text { (derajat kepercayaan CI : 95\% dengan kemaknaan 5\%) } \\
\mathrm{Z}_{\square} & =0,842 \text { (power 80\%) } \\
\mathrm{P} & =\text { Prakiraan proporsi } \\
\mathrm{Q} & =1-\mathrm{P} \\
\mathrm{P}_{1} & =\text { Prakiraan proporsi risiko hipertensi pada kelompok kasus } \\
\mathrm{OR} & =2,954 \\
\mathrm{P}_{2} & =\frac{b}{b+d}=\frac{26}{26+16}=\frac{26}{42}=0,62 \\
\mathrm{P}_{1} & =\frac{O R \cdot P_{2}}{\left(1-P_{2}\right)+\left(\text { OR.p } p_{2}\right)} \\
& =\frac{2,954 x 0,62}{(1-0,62)+(2,954+0,62)} \\
& =\frac{1,83148}{(0,38)+(3,574)} \\
& =\frac{1,83148}{3,954} \\
& =0,46 \\
& =\frac{O R}{(O R+1)} \\
& =0,75 \\
\mathrm{P} &
\end{array}
$$




$$
\begin{aligned}
& \mathrm{n}_{1}=\mathrm{n}_{2}=\frac{\left(z_{\alpha} \sqrt{2 P Q}+z_{\beta}{\sqrt{P_{1} Q_{2}+P_{2} Q_{2}}}^{2}\right.}{\left(P_{1}-P_{2}\right)^{2}} \\
& \mathrm{n}_{1}=\mathrm{n}_{2}=\frac{\left(1,96 \sqrt{2 \cdot 0,75 \cdot 0,25}+0,842 \sqrt{0,46 \cdot 0,54+0,62 \cdot 0,38)}^{2}\right.}{(0,46-0,62)^{2}} \\
& \mathrm{n}_{1}=\mathrm{n}_{2}=\frac{2.1167}{0,0256} \\
& \mathrm{n}_{1}=\mathrm{n}_{2}=82,7 \text { atau digenapkan menjadi } 83 \text { orang }
\end{aligned}
$$

Berdasarkan hasil perhitungan rumus besar sampel diperoleh sebanyak 83 orang, sehingga untuk seluruh sampel penelitian sebanyak 166 orang yang terdiri dari 83 responden untuk sampel kelompok kasus dan 83 orang untuk sampel kelompok kontrol.

\section{Teknik Pengambilan Sampel}

Sampel dalam penelitian ini adalah menggunakan teknik probability sampling yaitu teknik pengambilan sampel secara acak /random yang memberikan peluang yang sama bagi setiap unsur /anggota populasi untuk dipilih menjadi anggota sampel. Sampel diperoleh dengan menggunakan sistematik random dimana cara pengambilannya dengan membagi jumlah populasi dengan jumlah sampel yang ditentukan sampai jumlah sampel terpenuhi sesuai dengan yang diinginkan.

\section{Metode Penelitian}

Metode analisis data dalam penelitian ini menggunakan langkah-langkah sebagai berikut:

a. Analisis univariat

Berdasarkan hasil penelitian indeks massa tubuh menunjukkan bahwa pada kelompok kasus responden dengan indeks massa tubuh dalam kategori obesitas sebanyak 58 orang $(69,9 \%)$. Pada kelompok kontrol, responden dengan IMT obesitas sebanyak 6 orang (7,2\%). Indeks Massa Tubuh (IMT) responden dapat dilihat pada tabel berikut ini.

b. Analisis Bivariat

Hasil uji bivariat menunjukkan bahwa hasil $p<0,05$ artinya terdapat pengaruh yang signifikan antara indeks massa tubuh (IMT) terhadap kejadian hipertensi pada WUS di Wilayah Kerja Puskesmas Pulo Brayan tahun 2017. Pengaruh indeks massa tubuh (IMT) terhadap kejadian hipertensi pada WUS.

\section{HASIL DAN PEMBAHASAN}

Berdasarkan hasil penelitian, karakteristik yang ditanyakan pada responden yaitu umur, pendidikan, pekerjaan, jumlah anak, dan penghasilan perbulan. Umur responden pada kelompok kasus mayoritas berumur $>35$ tahun sebanyak 48 orang $(57,8 \%)$ minoritas berumur $<20$ tahun sebanyak 3 orang (3,6\%). Pada kelompok kontrol mayoritas berumur 20-35 tahun sebanyak 55 orang $(66,3 \%)$ minoritas berumur $<20$ tahun sebanyak 2 orang $(2,4 \%)$. Pendidikan responden pada kelompok kasus mayoritas berpendidikan menengah (SMA) sebanyak 49 orang $(59,0 \%)$ minoritas berpendidikan dasar (SD/SMP) sebanyak 3 orang $(3,6 \%)$. Pada kelompok kontrol mayoritas berpendidikan menengah (SMA) sebanyak 52 orang $(62,7 \%)$ minoritas berpendidikan dasar (SD/SMP) sebanyak 3 orang $(3,6 \%)$. Berdasarkan pekerjaan responden pada kelompok kasus mayoritas responden tidak bekerja sebanyak 56 orang $(67,5 \%)$, minoritas responden 
bekerja sebanyak 27 orang (32,5\%). Pada kelompok kontrol mayoritas juga tidak bekerja sebanyak 53 orang $(63,9 \%)$, minoritas responden bekerja sebanyak 30 orang $(36,1 \%)$.

Berdasarkan jumlah anak, pada kelompok kasus mayoritas responden mempunyai anak 2 orang sebanyak 35 orang $(42,2 \%)$, minoritas mempunyai anak 4 orang sebanyak 5 orang $(6,0 \%)$. Pada kelompok kontrol mayoritas responden juga mempunyai anak 2 orang sebanyak 34 orang $(41,0 \%)$, minoritas mempunyai anak 4 orang sebanyak 7 orang $(8,4 \%)$. Penghasilan per bulan responden didasarkan pada Upah Minimum Provinsi (UMP) Sumatera Utara tahun 2017 sebesar Rp. 2.528.815.-. Pada kelompok kasus mayoritas responden dengan pendapatan > Rp. 2.528.815.- sebanyak 50 orang $(60,2 \%)$, minoritas dengan pendapatan < Rp. 2.528.815.sebanyak 33 orang $(39,8 \%)$. Pada kelompok kontrol mayoritas responden dengan pendapatan $>$ Rp. 2.528.815.- sebanyak 55 orang $(66,3 \%)$, minoritas dengan pendapatan < Rp. 2.528.815.sebanyak 28 orang $(33,7 \%)$.

Tabel 2. Distribusi Responden Berdasarkan Indeks Massa Tubuh di Wilayah Kerja Puskesmas Pulo Brayan Tahun 2017

\begin{tabular}{ccccc}
\hline \multirow{2}{*}{$\begin{array}{c}\text { Indeks Massa Tubuh } \\
\text { (IMT) }\end{array}$} & \multicolumn{4}{c}{ Kejadian Hipertensi } \\
\cline { 2 - 5 } & \multicolumn{2}{c}{ Hipertensi } & \multicolumn{2}{c}{$\begin{array}{c}\text { Tidak Hipertensi } \\
\text { (Normal) }\end{array}$} \\
\cline { 2 - 5 } & $\mathbf{f}$ & $\mathbf{\%}$ & $\mathbf{f}$ & $\mathbf{\%}$ \\
\hline Obesitas & 58 & 69,9 & 6 & 7,2 \\
Normal & 25 & 30,1 & 77 & 92,8 \\
\hline Jumlah & $\mathbf{8 3}$ & $\mathbf{1 0 0 , 0}$ & $\mathbf{8 3}$ & $\mathbf{1 0 0 , 0}$ \\
\hline
\end{tabular}

Berdasarkan hasil penelitian indeks massa tubuh menunjukkan bahwa pada kelompok kasus responden dengan indeks massa tubuh dalam kategori obesitas sebanyak 58 orang $(69,9 \%)$. Pada kelompok kontrol, responden dengan IMT obesitas sebanyak 6 orang $(7,2 \%)$.

Tabel 3. Pengaruh Indeks Massa Tubuh terhadap Kejadian Hipertensi pada Wanita usia Subur (WUS) di Wilayah Kerja Puskesmas Pulo Brayan Tahun 2017

\begin{tabular}{|c|c|c|c|c|c|c|}
\hline \multirow{3}{*}{$\begin{array}{l}\text { Indeks Massa } \\
\text { Tubuh (IMT) }\end{array}$} & \multicolumn{4}{|c|}{ Kejadian Hipertensi } & \multirow{3}{*}{$p$} & \multirow{3}{*}{$\operatorname{Exp}(B)(95 \%$ CI $)$} \\
\hline & \multicolumn{2}{|c|}{ Hipertensi } & \multicolumn{2}{|c|}{$\begin{array}{c}\text { Tidak } \\
\text { Hipertensi } \\
\text { (Normal) }\end{array}$} & & \\
\hline & $\mathbf{F}$ & $\%$ & $\mathbf{f}$ & $\%$ & & \\
\hline Obesitas & 58 & 69,9 & 6 & 7,2 & \multirow{3}{*}{$<0,001$} & \multirow{3}{*}{$\begin{array}{c}29,773 \\
(11,469-77,290)\end{array}$} \\
\hline Normal & 25 & 30,1 & 77 & 92,8 & & \\
\hline Jumlah & 83 & 100,0 & 83 & 100,0 & & \\
\hline
\end{tabular}

Hasil uji bivariat menunjukkan bahwa hasil $p<0,05$ artinya terdapat pengaruh yang signifikan antara indeks massa tubuh (IMT) terhadap kejadian hipertensi pada wanita usia subur di Wilayah Kerja Puskesmas Pulo Brayan tahun 2017. Pengaruh indeks massa tubuh (IMT) terhadap kejadian hipertensi pada wanita usia subur (WUS) 


\section{KESIMPULAN DAN SARAN}

\section{Kesimpulan}

Berdasarkan hasil penelitian yang telah dilakukan dan disajikan pembahasan pada bab sebelumnya dapat disimpulkan bahwa: Indeks massa tubuh (IMT) berhubungan signifikan terhadap kejadian hipertensi pada wanita usia subur di Wilayah Kerja Puskesmas Pulo Brayan tahun 2017. $p=<0,001<0,05$. WUS dengan indeks massa tubuh obesitas meningkatkan terjadinya tekanan darah.

\section{Saran}

1. Disarankan kepada Wanita usia subur (WUS) yang mengalami peningkatan tekanan darah sistolik $\geq 140 \mathrm{mmHg}$ dan atau diastolik $\geq 90 \mathrm{mmHg}$ untuk segera melakukan pemeriksaan kesehatan secara menyeluruh ke tenaga kesehatan

2. Wanita usia subur (WUS) yang mengalami obesitas disarankan untuk menjalani pola makan sehat serta mengonsumsi makanan dengan gizi seimbang agar berat badan turun serta tekanan darah menjadi normal.

\section{REFERENSI}

Beevers. 2012. Faktor-faktor yang Berhubungan dengan Kejadian Hipertensi. Jakarta: Putra Pustaka.

Bungawati, D. dan Pratama, K.A. 2011. Kajian Indeks Massa Tubuh (IMT) Terhadap Tekanan Darah Pada Perawat di Rumah Sakit Baptis Kediri, Jurnal STIKES RS. Baptis Kediri Volume 4, No. 2, Desember 2011, ISSN 2085-0921

Davey, P. 2012. At a Glance Medicine. Terjemahan oleh Annisa Rahmalia dan Cut Novianty. Jakarta: Airlangga.

Dewi, S. dan Familia, 2010. Hidup Bahagia Bersama Hipertensi. Jakarta : A Plus Books.

Dien, N.G. 2014. Hubungan Indeks Massa Tubuh (IMT) Dengan Tekanan Darah pada Penderita Hipertensi di Poliklinik Hipertensi Dan Nefrologi BLU RSUP Prof. DR. R.D. Kandou Manado. Manado: Program Studi Ilmu Keperawatan Fakultas Kedokteran Universitas Sam Ratulangi.

Dinkes Propsu. 2014. Profil Kesehatan Sumatera Utara tahun 2013. Medan: Dinas Kesehatan Propinsi Sumatera Utara.

Guyton H. 2014. Fisiologi Kedokteran. Terjemahan oleh Irawati Setiawan, Ken Ariata Tengadi dan Alex Santoso. Jakarta: Penerbit Buku Kedokteran EGC.

James PA, dkk. 2014. Evidence-based guideline for the management of high blood pressure in adult report from the pane members appointed to the eighth joint national committee (JNC8). Jama. 2014; 311(5): 507-520.

Kemenkes RI. 2013. Riset Kesehatan Dasar tahun 2013. Jakarta: Kementerian Kesehatan Republik Indonesia.

Muhammadun. 2014. Hipertensi, Pedoman Klinis dan Terapi. Cetakan Pertama, Jakarta: Hipokrates.

Sanif, M.E. 2013. Hipertensi pada Wanita. Jakarta: EGC.

Sitepu, M. 2013. Segala Sesuatu yang Perlu Anda Ketahui Disease Penyakit, Jakarta: Gramedia Pustaka Utama.

Sumardiyono. 2015. Pengaruh Indeks Massa Tubuh (IMT) Terhadap Tekanan Darah Pada Pekerja Yang Terpapar Bising Industri Di Surakarta. Seminar Nasional Hasil - Hasil Penelitian dan Pengabdian LPPM Universitas Muhammadiyah Purwokerto. 
Sumayku, Irene Moudy. 2014. Hubungan Indeks Massa Tubuh dan Lingkar Pinggang dengan Tekanan Darah pada Mahasiswa Fakultas Kedokteran Universitas Sam Ratulangi. Jurnal eCliniC (eCl), Volume 2, Nomor 2, Juli 2014.

Sundaram KR, Sudhakar A, Kumar RK et al. 2009. Body Mass Index Trend And Its Association With Blood Pressure Distribution In Children.

Tapan. Erik. 2015. Obesitas Diikuti Pelbagai Macam Penyakit. Penyakit degeneratif. Jakarta : Gramedia. 
PENGARUH INDEKS MASSA TUBUH (IMT) TERHADAP KEJADIAN HIPERTENSI PADA WANITA USIA SUBUR (WUS) DI WILAYAH PUSKESMAS PULO BRAYAN MEDAN TAHUN 2017
Debora Lestari Simamora, et.al. 